\title{
METAMORFOSIS GERMÁNICAS DE DON QUIJOTE
}

\author{
María Luisa Esteve Montenegro \\ Universidad Complutense de Madrid
}

\begin{abstract}
Denn die Wirklichkeit ist, wenn sie den Menschen einschließt, nicht nur das, was sie ist, sondern auch alles, war ihr fehlt, alles was sie noch werden muß...'
\end{abstract}

Roger Garaudy

Estas palabras de Garaudy las podríamos aplicar a la figura de Don Quijote e incluso a la obra cervantina vista por sus admiradores e imitadores, dando lugar a lo que podríamos denominar metamorfosis de la obra.

Siguiendo esa línea, en este trabajo voy a hablar de las diferentes transformaciones a la que es sometida esta novela y con clla su figura principal en el ámbito cultural de habla alemana del siglo XVIII. Por un lado están las traducciones de la obra, por otro sus imitadores.

Ya las diferentes traducciones de la obra constituyen también una especie de metamorfosis. La primera que aparece, aunque parcial, se publica en 1617 y se hizo a partir de una versión francesa. Se trata de "El curioso impertinente", de la primera parte del Quijote, junto con algunas de las Novelas ejemplares como "Rinconete y Cortadillo" en la versión de Ulenhart, en la que los nombres de los personajes aparecen traducidos al alemán y son conocidos bajo la denominación de Isaac Winckelfelder y Jobst von der Schneidt. En 1648, en el año en que se firma la Paz de Westfalia dando lugar al final de la Guerra de los Treinta Años y, por tanto, en pleno período barroco alemán, aparece en Frankfurt una traducción directa del español auß 3 Hispanischer Spraach in Hochteutsche übersetzt (Zimmermann 1997: 289) que sólo llega hasta el capítulo 23, omitiendo, además, todas las historias intercaladas, así como canciones y versos que salpican toda la obra: lo único que le interesa al traductor es la historia del caballero que pierde la razón. Su autor, que aparecerá bajo el pseudónimo de Pahsch Bastel von der Sohle, detrás del cual se esconde el nombre de Joachim Cacsar, logra una buena versión alemana del Quijote. Será el único traductor del Quijote al alemán que no sólo domina el español sino que también ha viajado por España y se ha ocupado en seguir el rastro de las versiones de la obra cervantina en otros países y, por tanto, en otras lenguas. Todo

1.- «Pues la realidad es, cuando incluye al hombre, no sólo lo que es, sino todo aquello que le falta, todo lo que todavía ha de llegar ser...» 


\section{METAMORFOSIS GERMÁNICAS DE DON QUIJOTE}

ello le lleva a poder desarrollar sus propias teorías acerca de la traducción de esta obra. En primer lugar le concede gran importancia a la fidelidad al original, utiliza un lenguaje comprensible para el lector alemán, busca las equivalencias alemanas de los refranes y, como domina el lenguaje popular, lo mezcla también con expresiones arcaicas para darle a la lengua agilidad y parecido con el original. De este modo logra un auténtico Don Kichote alemán convirtiendo a Don Quijote en Don Kichote de la Mantzscha, das ist Juncker Harnisch auss Fleckenland para que incluso en el campo fonético no hubiese lugar a duda alguna y cuidando, ante todo, los nombre propios. Esta minuciosidad no impide que haya introducido cambios en el texto original, al suprimir historias intercaladas, poesías y canciones, como se mencionaba más arriba.

Hasta llegar a 1775, año en que se publica una nueva traducción del Quijote a partir del original español, versión que llevó a cabo en Weimar Friedrich Justin Bertuch, sólo aparecerán nuevas traducciones tomando como base las francesas que no se atienen por completo al original, sino que transforman el contenido afrancesándolo. Ese afrancesamiento consiste en que la historia no termina de un modo definitivo como la escribió Cervantes, sino que ofrece la posibilidad de una continuación. Para ello es necesario que el caballero andante no muera, lo cual permitiría que cl héroe volvicra a salir en busca de nuevas aventuras. De ese estilo es la versión anónima que aparece 1682 en Basilea y Frankfurt, así como una continuación del Quijote de Filleau de SaintMartin de 1696. Lo característico de estas versiones y de otras posteriores es que no sólo se parte de la versión francesa, sino que incluso dominan las interpretaciones francesas como se puede apreciar en el prólogo de una traducción anónima publicada en 1734 en Leipzig. Basándose en la opinión de Saint-Evremond, el traductor escribe que toda su vida va a seguir leyendo la historia de Don Quijote sin jamás cansarse y añade, además, que entre todos los libros que ha leído le hubiese gustado mucho haber sido el autor de éste porque, según él, «es el adecuado para enseñarnos el buen gusto en todo tipo de situaciones». Apoyándose en tal autoridad y considerando que se trata de una obra de buen gusto cree que se ha escrito «para subsanar el mal gusto de la nación española y, Cervantes que es un hombre inteligente, como no puede soportar el mal gusto de su país ha intentado mejorarlo en algo con su libro» (Brüggemann 1958: 43). Lo curioso es que la opinión de Saint-Evremond va a llegar incluso hasta la época de Lessing, que no se llegó a manifestar de un modo expreso acerca de la genialidad de Cervantes.

No obstante, después de estas versiones de la novela cervantina, el traductor que logra darle un gran impulso a la obra de Cervantes y despertar el interés por la literatura española hasta después del Romanticismo, será Bertuch con una traducción directa del español, pero sólo de la primera parte del Quijote que apareció publicada en 6 libros seguida de la traducción del Quijote de Avellaneda en vez de haber traducido también la segunda parte del Quijote cervantino. Para llevar a cabo este trabajo echa mano de diferentes traducciones, incluidas las francesas, e incluso para la introducción a su traducción consulta la biografía de Cervantes de Mayans y Siscar presentándonos así a un Don Quijote que es imagen y reflejo del Schwärmer es decir del "entusiasta", del "exaltado romántico". Para Bertuch Sancho es, por el contrario, «la fiel imagen del pucblo crédulo, supersticioso, codicioso, falaz, charlatán, mentiroso, glotón, vago, miedoso, cobarde, vulgar, ignorante y hasta donde alcanzan sus cinco sentidos capaz de juzgar bien, actuar más siguiendo la norma de la costumbre que reflexionando, reconocer las equivocaciones $\mathrm{y}, \sin$ embargo, seguirlas ciegamente» (Bertuch 1875: X). Y como Mayans critica el Curioso impertinente y el Cautivo, Bertuch aprovecha para excluir la primera historia y reducir la otra igual que hizo con la de Marcela y Grisóstomo, la de Cardenio y Dorotea porque, según él, esta exclusión no afectaba al contenido de la obra (Brüggemann 1958: 45). A pesar de esos posibles fallos, la labor iniciada por Bertuch en Weimar será todavía reconocida años más tarde por August Wilhelm Schlegel cuando comenta la traducción del romántico Ludwig Tieck. En esta ocasión no puede menos que admitir que Bertuch es el precursor de esa popularidad que España llega a alcanzar dentro del panorama de la literatura alemana de finales del XVIII, aunque no esté del todo conforme con la visión un tanto cómica y burlesca que se ha dado de la figura quijotesca. Lo cual no impide que precisamente estos rasgos hayan contribuido, en parte, a la popularización de la novela. Para 


\section{MARÍA LUISA ESTEVE MONTENEGRO}

Schlegel, la obra no está exenta de una estética romántica; para Böhl de Faber el acierto del Quijote radica más en el arte romántico que en esa intencionada sátira, pues la oposición que se establece entre realidad e ideal impregna todas sus páginas y aparece representada de un modo tan real que conmueve a cualquier lector; en algunos pasajes lo divierten, en otros lo emocionan y en otros lo elevan (Zimmermann 1997: 292). La humanidad de Don Quijote, la sátira cervantina, la relación dialógica entre los dos personajes principales, entre las dos culturas que representan, la aristocrática y la popular (Neuschäfer 2001: 108) contribuyen a esa interpretación romántica. Y de pronto, a través del Quijote España se convierte en el país anhelado por el romántico, -igual que lo fue Italia y el mundo clásico para Winckelmann y Goethe-, y Cervantes en el poeta que contribuye a superar la antigua mitología y sustituirla, como dice Schlegel, por una nueva que se forma en lo más profundo del espíritu (Brüggemann 1958: 51).

Este interés por la literatura española contribuye a que se proyectara una nueva traducción del Quijote directamente del castellano. Al no estar dispuesto August Wilhelm Schlegel a llevarla a cabo, la elección recae en Ludwig Tieck, a pesar de que sus conocimientos de la lengua española no eran tan profundos; no obstante, logra que en su versión se ponga de manifiesto la atmósfera y el espíritu de la novela cervantina. Sus dotes literarias, junto con las recomendaciones y los consejos de ambos hermanos Schlegel, contribuyen a una muy buena recreación de la novela que, ante todo, se pone de manifiesto a partir del tercer libro.

Al comenzar el trabajo Tieck se apoya mucho en la traducción de Bertuch, para, según va avanzando, ir independizándose poco a poco de este modelo. Comparando el original y su traducción se comprueba que sigue el texto cervantino muy de cerca, lo cual no impide que suprima dos poemas del principio y que divida la obra en doce libros. Cuando aparecen proverbios y refranes trata de buscar las equivalencias en alemán, a pesar de que desconoce términos del lenguaje coloquial; de ahí que su Sancho se convierta en un personaje demasiado distinguido y su Don Quijote carezca del carácter andariego. Para el ideal romántico, todo clemento en la novela cervantina poseía, no sólo para el traductor sino también para Schlegel como crítico, importancia estética dentro de la composición de la obra. Lo que interesa no son tanto las aventuras de Don Quijote como la figura del caballero y sus nobles sentimientos.

Las metamorfosis a las que se va a ver sometida la novela de Cervantes en el siglo XVIII en Alemania no se limitarán a las traducciones. Existe otro tipo de transformación que incluye por una lado, la recepción ficcional basada en la imitación o en la parodia de la obra, es decir, también de la figura original de Don Quijote y por otro, obras en las que se aprecia su influencia.

A medio camino entre las dos traducciones realizadas a partir del original español mencionadas más arriba, y todavía dentro del período de la Ilustración alemana, en pleno apogeo de la popularidad de la obra cervantina, Christoph Martin Wieland (1733-1813) publica en 1764 y de forma anónima su obra Der Sieg der Natur über die Schwärmerey oder Die Abenteuer des Don Sylvio von Rosalva. Eine Geschichte worinn alles Wunderbare natïrlich zugeht (El triunfo de la naturaleza sobre el entusiasmo o Las aventuras de Don Silvio de Rosalva. Una historia en donde todo lo maravilloso ocurre de forma natural). Se trata de una mezcla de parodia e imitación del ingenioso hidalgo al que toma como modelo, inspirándose también en otros temas de la obra aunque no siempre fueran equivalentes.

La obra de Cervantes no era desconocida en el mundo literario de la época. Desde la perspectiva de su temática y de su estilo se había convertido en el modelo de novela moderna europea que pretendía alcjarse del modelo heroico-galante y de aventuras imperante en aquel momento, y la Ilustración la veía como un ataque o una sátira a todo lo que fuera ilusorio o fantástico.

La idea de Wieland de escoger la temática quijotesca para Don Sylvio data de su estancia en Biberach en torno al año 1762, de cuando frecuentaba la biblioteca del castillo de Warthausen, donde tiene ocasión de entrar en contacto con la cultura rococó francesa, muy apreciada entonces por la nobleza alemana. Allí es donde vuelve a relcer a Cervantes y a otros autores clásicos. Fiel 


\section{METAMORFOSIS GERMÁNICAS DE DON QUIJOTE}

a su modelo cervantino, equipara ficción y realidad como núcleo de su temática y lo encarna en la figura de un Schwärmer; de un entusiasta idealista que quiere renovar el universo de sus lecturas; sólo que en el caso de Don Sylvio son los Contes de fées en vez de los libros de caballería.

Siguiendo el modelo del Quijote, ilustrándolo con diversos motivos hispanos, bien de tipo geográfico-cultural, mencionando acontecimientos de la historia de España como pueden ser la Inquisición o la Guerra de Sucesión, en otros casos nombres de personajes conocidos de la literatura española como el Cid o Guzmán de Alfarache, Wieland consigue dar la impresión de que se mucve cómodamente $\mathrm{cn} \mathrm{cl}$ ambiente español. Con estos recursos consigue recrear la vida auténtica en la ficción narrativa como soporte de esa realidad a la que se quicre sustraer el joven Don Sylvio dominado por su desmedido entusiasmo. Todo este ambiente español era real y a su vez conocido por el lector alemán a través de la novela picaresca, de las Novelas ejemplares de Cervantes así como de la adaptación que Lesage había hecho de novelas españolas, sobre todo el Gil Blas de Santillana.

El contenido de Don Sylvio gira en torno a su figura, que al igual que Don Quijote, vive aislado en un castillo administrado por su tía, Donna Mencia, a la que el padre del joven le ha encomendado su educación. En la soledad de la mansión y sin que nadie tenga conocimiento de cllo, Don Sylvio se dedica a alimentar su propia fantasía con la lectura de los libros de cuentos de hadas que llenan la biblioteca del castillo y que por un azar había descubierto. Todos ellos estaban encuadernados en color azul, el color simbólico de las colecciones de ese tipo de cuentos. Tanto leyó que su imaginación le hace abandonar el ámbito de la realidad y llega a creer que los personajes fantásticos, los magos y las hadas de esos cuentos son seres que habitan en el mundo real y, al ser reales, desea incluso llegar a conocerlos. La ficción y la realidad se entremezclan, y como si estuviera soñando despierto, en su mundo aparecen las hadas. Un día, paseando por el parque caza una mariposa azul (otra vez aparece el color azul que encontraremos de nuevo en el Romanticismo), pero llevado por la compasión la libera poco después. A continuación encuentra entre la hierba una miniatura que contiene el retrato de una joven de la cual se enamora al instante. En su fantasía establece una relación entre ambos sucesos, entre la mariposa y el retrato; en un estado de semiinconsciencia el hada Radiante promete ayudarle a encontrar a la princesa del retrato si a cambio él le ayuda a deshacer el maleficio que la ha convertido en mariposa. Mientras sucede todo esto, la tía del protagonista está muy ocupada en buscarle una novia adecuada a su condición. Pero el joven, contrario a estas intenciones familiares, aprovecha para abandonar a escondidas la casa paterna haciéndose acompañar de su criado Pedrillo y de su perrito Pimpimp, figuras éstas que se corresponden a las de Sancho Panza y Rocinante. Este Sancho Panza, aunque más joven, posec los mismos rasgos de sencillez, temor, gusto por los placeres mundanos todo ello unido a una gran bondad y fidelidad al igual que el personaje cervantino. Emulando a su modelo, también habla mucho, emplea refranes en sus diálogos y trastoca todos los nombres extranjeros. El tema del caballero andante tomado de Cervantes está aquí presente, sólo que las metas que persiguen ambas figuras son diferentes. A Don Sylvio no le mueve el afán de aventuras sino que persigue un fin concreto: romper el encantamiento de ese hada que le ha prometido ayudarle a encontrar a su dama. Él sólo busca felicidad y amor, no pretende en modo alguno combatir la injusticia en el mundo, no es como Don Quijote un Schwärmer, un cntusiasmado heroico y trágico que, siguiendo la tradición del noble caballero, lucha por la justicia llevado por las elevadas leyes de la caballería. Tampoco aparece aquí la soñada Dulcinea cervantina sino una ingenua mariposa azul y un retrato que parecen conducir a un final real.

Volviendo al contenido de la novela, después de una serie de complicaciones en las que siguiendo la tónica de la obra es difícil establecer la distinción entre sueño y realidad -lo mismo sucede en cl Quijote-, hasta el punto que Don Sylvio llega a confundir a su fiel Pedrillo con el enano verde y por poco lo ahoga, tienen lugar entonces dos encuentros significativos: ambos "héroes" impiden que la amada de Don Eugenio (hermano de Donna Felicia) sea raptada pero, a su vez, Donna Felicia por azar tiene ocasión de ver por primera vez a Don Sylvio mientras éste 


\section{MARÍA LUISA ESTEVE MONTENEGRO}

dormía. $\mathrm{Al}$ instante se enamora del joven durmiente. Toda la trama va acompañada de una serie de confusiones y de intentos de aclararlos, de una lucha entre la realidad y la fantasía provocada por esas lecturas llenas de fantasía de los cuentos de hadas de las que tampoco se libra Pedrillo, a pesar de sus muchos momentos de lucidez. Por fin los dos aventureros se encuentran con Don Eugenio en su palacio, que Don Silvio, en su desorientación, había tomado por la morada de las hadas. Ambos personajes son invitados a quedarse en señal de agradecimiento. Donna Felicia aprovecha esta circunstancia para intentar "curar" a Don Sylvio de su desmedido entusiasmo, cosa que logra con ayuda de Don Gabriel, un viejo amigo de la familia. Y como en los cuentos a los que tan aficionado era Wieland, la felicidad se ve colmada cuando se descubre el doble lazo que los une: que la amada de Don Eugenio, Hyacinthe, era nada menos que Donna Seraphina von Rosalva, hermana de Don Sylvio, que de niña había sido raptada por unos gitanos. Aquí la influencia no es quijotesca sino de las Novelas ejemplares. Donna Mencia entra en escena en el último momento de toda esta trama y se pasa a informarla de todas las novedades acaecidas hasta ese instante. El final de la novela se cierra con un topos convencional: con una triple boda en la que Pedrillo también es protagonista. El resultado de tanta fantástica peripecia es que el loco enamorado de un fantasma se cura rápidamente ante la presencia de una mujer real y no soñada. El final es menos trágico que el ccrvantino. Don Quijote, en cambio, acepta la cruda realidad al final, en el lecho mortuorio.

A través de esta síntesis de la obra se puede apreciar que las fuentes que le sirven de inspiración a Wieland para esta novela no se limitan únicamente a Cervantes. La moda francesa de los contes des Fées de finales del siglo XVII y principios del XVIII en contra del espíritu clásico, muy en boga entre el lector culto alemán, permite al novelista poner en boca del personaje principal toda su interpretación sobre la confusión entre fantasía y realidad que había tomado de esos cuentos; estos, a su vez, presentan motivos orientales recogidos de Las mil y una noches, de la novela pastoril o de la novela heroico-galante contra los que arremete por medio de la sátira. Sus modelos habían sido la baronesa d'Aulnoy (1650-1705), la condesa Murat (1670-1716) así como Perrault (1628-1703). Del conde Hamilton y de Crébillon toma el estilo satírico de sus cuentos en los que parodian todas las extravagancias y el mal gusto.

En esta conjunción del Quijote y los contes des Fées domina en lo esencial la influencia cervantina, sobre todo en la primera parte de la obra. Prueba de ello es el comienzo de la novela con un estilo muy alcjado de la narrativa alemana de la época y en cambio muy próximo al autor español:

In einem alten baufälligen Schloß der spanischen Provinz Valencia lebte vor einigen Jahren ein Frauenzimmer von Stande, die zu derjenigen Zeit, da sie in der folgenden Geschichte ihre Rolle spielte, bereits sechzig Jahre unter den Namen Donna Mencia von Rosalva sehr wenig Aufsehens in der Welt gemacht hatte (Wieland 1997: 15).

[En un vicjo y ruinoso palacio de la provincia española de Valencia hace unos años que vivía una dama de categoria llamada Donna Mencia von Rosalva que hasta aquel momento y puesto que en la siguiente historia desempeña su papel, había llamado muy poco la atención durante sesenta años].

El triángulo formado por la combinación de lugar, tiempo y personaje con el que comienza la obra despierta inmediatamente el interés del lector y le introduce de un modo natural en el curso narrativo de la novela.

En la obra de Wieland y concretamente en la figura principal se detecta una tercera influencia: la del suizo Johann Jacob Bodmer (1698-1783) que ya en su Critische Betrachtungen über die Poetischen Gemählde der Dichter (1741) había escrito un capítulo sobre el carácter de Don Quijote y Sancho Panza y que, sin habérselo propuesto, Wieland había seguido. Él sabe, pues había sido su discípulo, que Bodmer no considera la novela cervantina como pura sátira, sino que ante todo expone un estado psíquico complejo en el que la imaginación y las fantasías de Don Quijote forman parte del lado irracional de su carácter. No obstante, junto a este aspecto da muestras de 


\section{METAMORFOSIS GERMÁNICAS DE DON QUIJOTE}

poseer una gran sabiduría apareciendo locura y sabiduría en una misma personalidad (Bodmer 1971: 523-524, 528).

Siguiendo los aspectos que Bodmer había considerado relevantes, la obra de Wieland gira entorno a la curación de ese desmedido entusiasmo del protagonista motivado por su desbordante imaginación, algo que llega a conseguir en el momento de su matrimonio. Es en ese instante cuando se produce el paso definitivo de la fantasía a la realidad.

Wieland también tiene presente las observaciones de Bodmer acerca de esa especie de cortesía bien educada denominada galantería (Bodmer 1971: 519) de la que Don Quijote es poseedor. Como contrapartida a estas cualidades el novelista alemán opone en Don Sylvio una belleza de cuerpo y alma que dan lugar a que su héroe se enamore perdidamente del retrato de una joven «como jamás lo había estado en su Dulcinea o Amaryllis un caballero andante o un pastor arcádico» (Wieland 1997: 36). De modo recíproco Donna Felicia también sucumbe ante la belleza amable del durmiente Don Sylvio.

En la figura de Pedrillo, a pesar de tratarse de una versión joven de Sancho Panza, se reconocen los mismos rasgos que en el escudero cervantino que, a su vez, coinciden con el comentario de Bodmer al respecto. Éste considera que Sancho posee una inteligencia natural, aunque sin cultivar y que sólo unas cuantas reglas campesinas y la experiencia adquirida en la vida rural le bastaban para distinguir las locuras de su amo; a las fantasías de su señor únicamente se somete por la calidad de su argumentación y, en más de un caso, por un interés puramente egoísta (Bodmer 1971: 541).

La similitud entre los personajes de ambas obras también se puede detectar en diferentes situaciones. Los dos héroes tienen en común el carecer de una ocupación reglada, lo que les permite seguir el curso de sus inclinaciones sin sentirse atados por nada, y así,

[...] tan pronto como amanecía, ya estaba despierto; sacaba su cuaderno de debajo de la almohada y leía con mirada rápida un cuento detrás de otro (Wieland 2000: 25).

Él se enfrascó tanto en su lectura (de novelas de caballería), que se le pasaban las noches leyendo de claro en claro, y los días de turbio en turbio (Cervantes 1966: 20).

El paralelismo es casi literal cuando ambos personajes son descritos por Pedrillo en un caso y por una zagala en el otro:

「... él (refiriéndose a Don Sylvio) es el mejor, el más amable, más generoso, más bondadoso, más sabio y más valiente joven caballero en toda España (Wicland 2000: 155).

[...] es el más valiente, y el más enamorado, y el más comedido (señor) que tiene el mundo (Cervantes 1966: 859)

A veces, incluso se encuentran refranes prácticamente iguales en ambas novelas:

$[\ldots]$ de noche todas las vacas son negras (Wieland 2000: 110).

[...] de noche todos los gatos son pardos (Cervantes 1966: 706).

Como ejemplo conocido de coincidencia en la trama se podría citar la noche en que Pedrillo confunde los robles del bosque con terribles gigantes cubiertos por cientos de brazos y piernas y lleno de pavor le dice a su amo:

¿Que Dios nos asista! [... ¿no veis ahí al terrible gigante que de pronto sale ahí del suelo? (Wieland 2000: 98).

A lo que Don Sylvio esta vez anclado en el mundo de la realidad le contesta:

Te digo bobo majadero, [...] que es un árbol: lo que tú consideras brazos son sus ramas (Wieland 2000: 98).

Aquí es Don Quijote el que confunde los molinos de viento 


\section{MARÍA LUISA ESTEVE MONTENEGRO}

$[\ldots]$ con treinta, o poco más, desaforados gigantes $[\ldots]$ de los brazos largos, que los suelen tener algunos de casi dos leguas (Cervantes 1966: 65),

y Sancho trata, en vano, de convencerlo de lo contrario:

Aquellos que allí se parecen no son gigantes, sino molinos de viento, y los que en ellos parecen brazos son las aspas, que volteadas del viento, hacen andar la piedra del molino (Cervantes 1966: 65).

El parecido es, pues, manifiesto en ambas obras, no sólo en coincidencias temáticas sino también en la percepción ficcional de la realidad. Don Quijote no se mueve en el mundo fantástico de las novelas de caballería alejado de la realidad, sino que la percibe e interpreta desde una falsa perspectiva. Lo mismo le sucede a Don Sylvio, que lo hace desde la lógica de los cuentos de hadas. Sólo que en Don Sylvio se percibe bajo el disfraz novelesco una intención didáctica propia de la Ilustración que quiere contrarrestar las consecuencias del entusiasmo por medio de la ironía y el humor (Zimmermann 1997: 303). Wieland está más en la línea de las denominadas quijotadas del Rococó, lo cual no impide que Don Silvio constituya el eslabón que mantiene la tradición quijotesca desde la Ilustración al Romanticismo y sirva de inspiración a otras metamorfosis posteriores.

\section{Bibliografía}

Brender, I. (1998): Christoph Martín Wieland. Reinbeck/Hamburgo: Rowohlt.

Briesemeister, D. (1984): "La recepción de la literatura española en Alemania en el siglo XVIII", Revista de Fïlología Hispánica, 33, 285-310.

Bodmer, J. J. (1971): Kritische Betrachtungen über die Poetischen Gemälde der Dichter, Frankfurt/ Meno: Athenäum.

Brüggemann, W. (1958): Cervantes und die Figur des Don Quijote in Kunstanschauung und Dichtung der deutschen Romanti, Munster: Aschendorff.

Cervantes Saavedra, M. de (1966): Don Quijote de la Mancha, Madrid: Ediciones Castilla.

Cervantes Saavedra, M. de (1648): Don Quichote de la Mantzscha. Das ist: Juncker Harnisch auss Fleckenland. Trad. de J. Caesar, Frankfurt/Meno.

Cervantes Saavedra, M. de (1775): Leben und Taten des weisen Junkers Don Quixote de la Mancha. Del original de Cervantes junto con la continuación del de Avellaneda. Trad. de F. J. Bertuch, Weimar/Leipzig: Fritsch.

Cervantes Saavedra, M. de (s. a.): Leben und Taten des scharfsinnigen Edlen Don Quijote de la Mancha. Traducción de Ludwig Tieck, Leipzig: Philipp Reclam jun.

Cervantes Saavedra, M. de (1870): Der sinnreiche Junker Don Quixote von La Mancha. Introducción de Heinrich Heine, Stuttgart: Nieger'sche Verlagsbuchhandlung.

Cervantes Saavedra, M. de (s. a.): Cervantes' Don Quijote. Traducción de Edmund Zoller, Leipzig: Verlag des Bibliographischen Instituts.

Hoffmeister, G. (1976): España y Alemania. Historia y documentación de sus relaciones literarias, Madrid: Gredos.

Neuschäfer, H.-J. (2001): "Cervantes, Don Quijote", en R. Brandt (ed.), Meisterwerke der Literatur von Homer bis Musil, Leipzig: Reclam, 108-128.

Rodick, Ch. (ed.) (2000): Dresden und Spanien, Frankfurt/Meno: Vervuert.

Vega, M. y Wegener, H. (cds.) (2002): España y Alemania. Percepciones mutuas de cinco siglos de Historia, Madrid: Editorial Complutense. 


\section{METAMORFOSIS GERMÁNICAS DE DON QUIJOTE}

Wieland, Ch. M. (1997): Der Sieg der Natur über die Schwärmerey oder die Abentheuer des Don Silvio von Rosalva. Ed.: Reemtsma, Jan Ph. y Radspieler, H. y J., Zurich: Haffmans.

Wieland, Ch. M. (2001): Die Abenteuer des Don Sylvio von Rosalva. Ed.: Sven-Aage Joergensen, Stuttgart: Reclam.

Wieland, Ch.. M. (1963ss.): Briefwechsel. Ed.: Deutsche Akademie der Wissenschaften zu Berlin durch H. W. Seiffert, Berlín: Akademie Verlag.

Zimmermann, Ch. von (1997) Reiseberichte und Romanzen. Kulturgeschichtliche Studien zur Perzeption und Rezeption Spaniens im deutschen Sprachraum des 18. Jahrhunderts, Tubinga: Niemeyer. 